\title{
The Implementation of Image Smoothing to Reduce Noise using Gaussian Filter
}

\author{
Ina Agustina \\ Universitas Nasional \\ Pasar Minggu, Jakarta, \\ Indonesia
}

\author{
Fauziah Nasir \\ Universitas Nasional \\ Pasar Minggu, Jakarta, \\ Indonesia
}

\author{
Anggit Setiawan \\ Universitas Nasional \\ Pasar Minggu, Jakarta, \\ Indonesia
}

\begin{abstract}
Nowadays information is very important and needed, especially for an image, but an image that we have often contains noise, such as black and white grains. To overcome this problem, it is possible to use image smoothing that image captured becomes smoother and is easier to be seen by one's eyes. The method used is Gaussian filtering. Gaussian filtering aims to decreace noise in an image. In this study, it uses an image affected by noise which is belong to Gaussian noise, Salt and Pepper noise, and Speckle noise. This study aims to smooth an image by decreasing noise on an image affected by noise that it becomes better than before. From the result of image reduction, it is possible to get the best image which has high value (RMSE:19.2960 db, PSNR:35.2761 db, SNR:30.9538 db) and in the experiment 1. jpg has a low value (RMSE:1185.5739 db, PSNR:17.3915db, SNR:13.2861db).
\end{abstract}

\section{General Terms}

Image Smoothing, Gaussian Filtering, Noise Reduction

\section{Keywords}

Image Smoothing, Gaussian Filtering, Noise reduction

\section{INTRODUCTION}

\subsection{Background}

Data or information is not only presented in a text format, but it is also possible to be presented in an image, audio, and video format. Those data is generally called Multimedia. In this information and technology era, all cannot be separated from Multimedia. Image is a representation, similarity, imitation of an object. Image which is well-known in computer is a digital image. Digital image can get a low quality or problem. Problem in a digital image is generally called noise. Noise is a problem caused by digital data storage which received by image data receiver which decrease image quality. Noise can be caused by optical instrument problem in image receiver, such as photo lens which is full of dust or unsuitable image process. There are three kinds of noise, namely Gaussian Noise, Salt and Pepper Noise, and Speckle Noise.

Operations used in image processing are so various. Image processing operatiom generally can be classified in some groups. One of them is image smoothing. Image smoothing is an operation aiming to improve image quality by manipulating image paramater and is a way to disappear noise. There are some methods of image smoothing. One of them is Gaussian filtering. Gaussian filter is one of filter using mathematics formula to create autofocus effect to reduce detail and create foggy effect determined by sigma value. The bigger sigma value of Gaussian filter, the blurrier result of filter.
Method that is used in this study is Gaussian filtering method. This application is expected to be capable of running well in reducing noise.

Those are some earlier journals related to the topic and discussion is used as reference to develop this research.

Dessy Purwanti "The Implementation of Gaussian Smoothing Method Used as Image Smoothing ". The weakness of this research is image format used is Bitmap (BMP) and JPG, and the output cannot be saved in the image processing 2[1].

Amril Mukmin Harahap "The Design and Implementation of Noise, Salt and Pepper Reduction Application Using Improved Median Filter Method". In this research, image calibration is only in one phase and there is no image quality calibration [2].

Andre Wedianto, "Analzying The Comparison of Gaussian Filter, Mean, and Median toward Noise reduction". The weakness of this research is no image quality calibration in jpg format and image calibrated is only one [3].

Gilang Juanda " Designing Noise Reduction in Digital Image Using WAVALET Based Method". The weakness of this research is no image quality calibration [4].

Dini Sundani " Image Smoothing Application Based Classic and Quantum Computation ". The weakness of this research is no image quality calibration and the image calibrated is only four in jpg format [5].

\subsection{Problem}

These are some problem will be investigated here.

1) Determining image data will be processed in image smoothing.

2) Implementing Gaussian filter and system in order to be an application used to reduce digital image noise.

3) Image used is an image originally affected by noise.

\subsection{Objectives}

These are some research objectives.

1) Creating image smoothing application to reduce noise using Gaussian filter.

2) Implementing system in order to be an application capable of processing image smoothing using Gaussian filter.

3) Calibrating original image using Gaussian filtering, including size, pixel, and image quality (RMSE, PSNR and SNR).

\section{METHODOLOGY}

The application production is conducted in some phases. The first phase is a plan. In this phase, it plans the basic concept of application and use of programming language. The second phase is designing application appearance which will be created. The next phase is a calibration. In this phase, the application will be tested. 


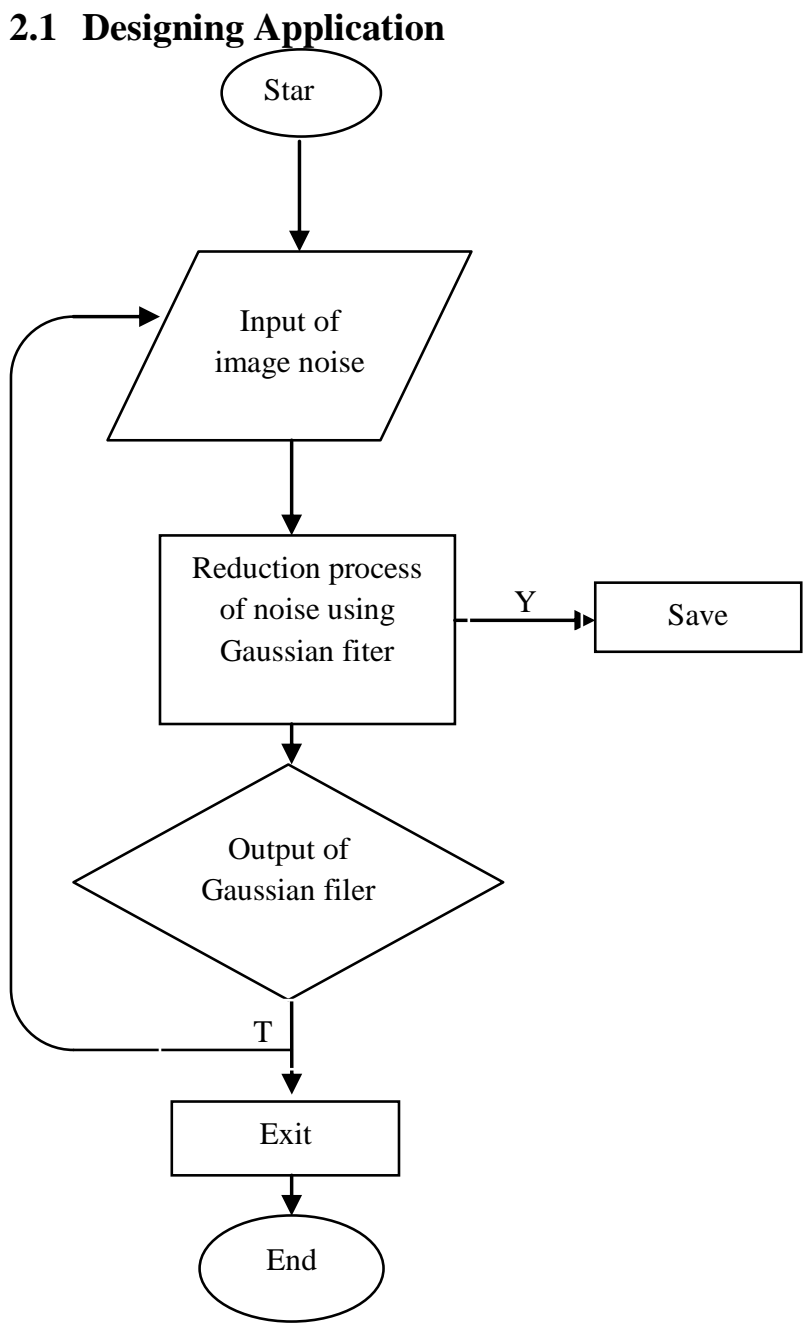

Fig. 1. Flowchart of Application Design

Design of image smoothing application starts from input of image noise. Then noise is reduced by Gaussian filter. From the output of Gaussian filtering, it is possible to save the picture of Gaussian filter output. If it is not done, it should be reprocessed or exit from the application.

\subsection{Designing Appearance}

Design of appearance is used to make an application in order to avoid obstacle in designing application interface which will be created. Design of this application consists of six buttons, namely choose image, grey noise, Gaussian filter, reprocess, save, and exit.

\subsection{Phase}

In calibration phase, the application will be tested by using ten different pictures and using a picture in PNG,BMP,JPG format. The output of Gaussian filter will be compared between the size and the original one. Then It will conduct image calibration by finding out the value of RMSE,PSNR and SNR which is in decibel (db).

\section{RESULT AND DISCUSSION}

\subsection{Discussion}

In this discussion, it will talk about application appearance and menu button used. Look at the picture below.

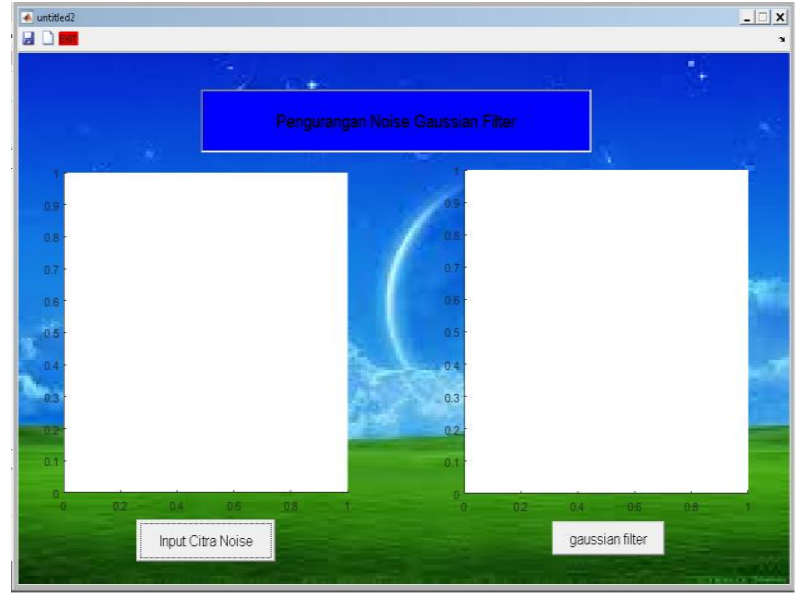

Fig. 2. Application Appearance

In the beginning appearance above, it consists of some menu buttons. For further information, look at the picture below.

1). Input of image noise

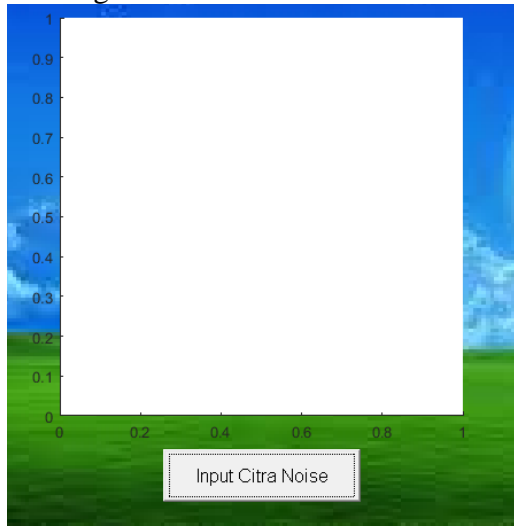

Fig. 3. Choose picture

Input of image noise is menu button to choose image affected by noise in jpg, bmp, and png format.

2). Gaussian Filter

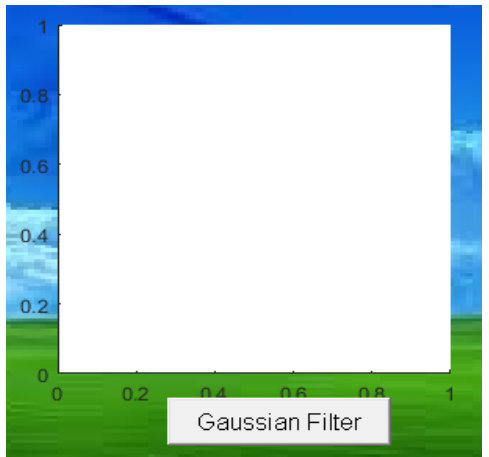

Fig. 4. Gaussian filter

Menu button of Gaussian filter is used to change an image affected by white grain noise become an better image which does not contain white grain noise by using Gaussian filter.

3). Save

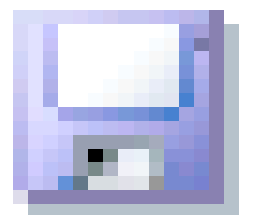

Fig. 5. Menu Button of Save 
Menu button of save is used to save the output of Gaussian filtering which in jpg format.

4). Reprocess

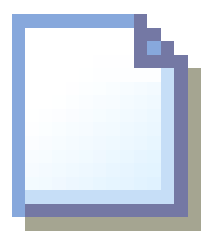

Fig. 6. Menu button of Reprocess

It is used to reprocess image smoothing from input of image noise

5).Exit

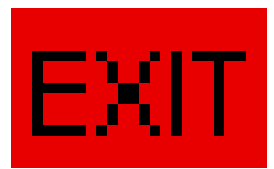

Fig. 7. Menu Button of Exit

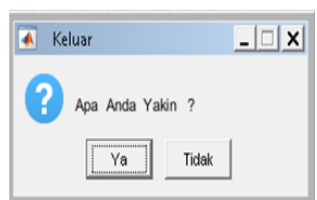

Fig. 8. Exit Notice

Menu button of exit is used to leave the application, if all is done. Before leaving the application, exit notice will appear.

\subsection{Calibrating}

This calibration is conducted by using ten images affected by noise and using an original image afftected by noise captured long time ago.

Table 1. Image Noise

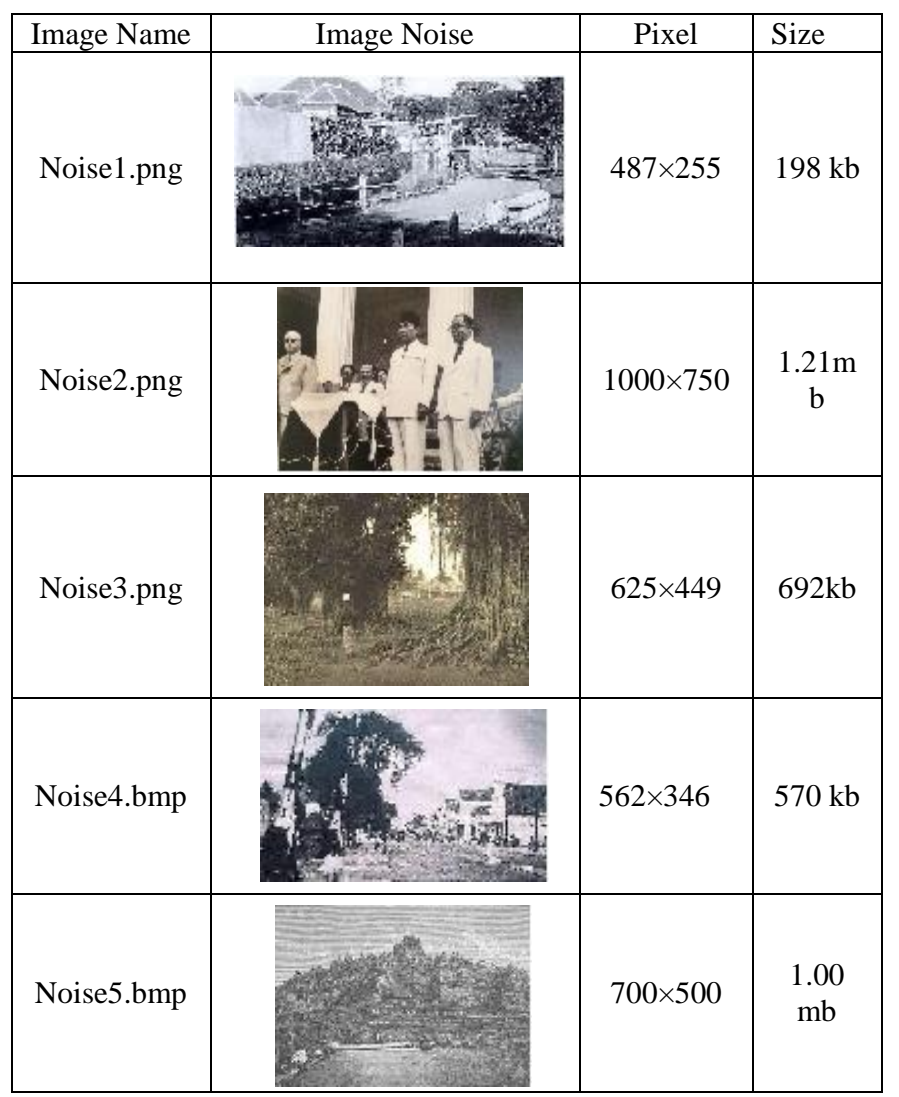

\begin{tabular}{|c|c|c|c|}
\hline Noise6.bmp & Le, & $400 \times 270$ & $316 \mathrm{~kb}$ \\
\hline Noise7.jpg & 6 & $677 \times 355$ & $48 \mathrm{~kb}$ \\
\hline Noise8.jpg & & $1024 \times 656$ & $552 \mathrm{~kb}$ \\
\hline Noise9.jpg & & $630 \times 937$ & $188 \mathrm{~kb}$ \\
\hline Noise10.jpg & 5 & $640 \times 410$ & $120 \mathrm{~kb}$ \\
\hline
\end{tabular}

From the table 1, it is known that all images have different noise, size, and format. Then the noise will be reduced by using Gaussian filter.

1).Calibrating Gaussian Filter

Table 2.Noise Reduction Using Gaussian Filter

\begin{tabular}{|c|c|c|c|}
\hline $\begin{array}{c}\text { Image } \\
\text { Name }\end{array}$ & Output of Gaussian filter & Size & Pixel \\
\hline $\begin{array}{c}\text { Pengujian } \\
\text { 1.jpg }\end{array}$ & & $24 \mathrm{~kb}$ & $487 \times 255$ \\
\hline $\begin{array}{c}\text { Pengujian } \\
\text { 2.jpg }\end{array}$ & & & \\
\hline $\begin{array}{c}\text { Pengujian } \\
\text { 3.jpg }\end{array}$ & & $\begin{array}{c}68.0 \\
\mathrm{~kb}\end{array}$ & $1000 \times 750$ \\
\hline $\begin{array}{c}\text { Pengujian } \\
\text { 4.jpg }\end{array}$ & & $\begin{array}{c}28.0 \\
\mathrm{~kb}\end{array}$ & $625 \times 449$ \\
\hline
\end{tabular}




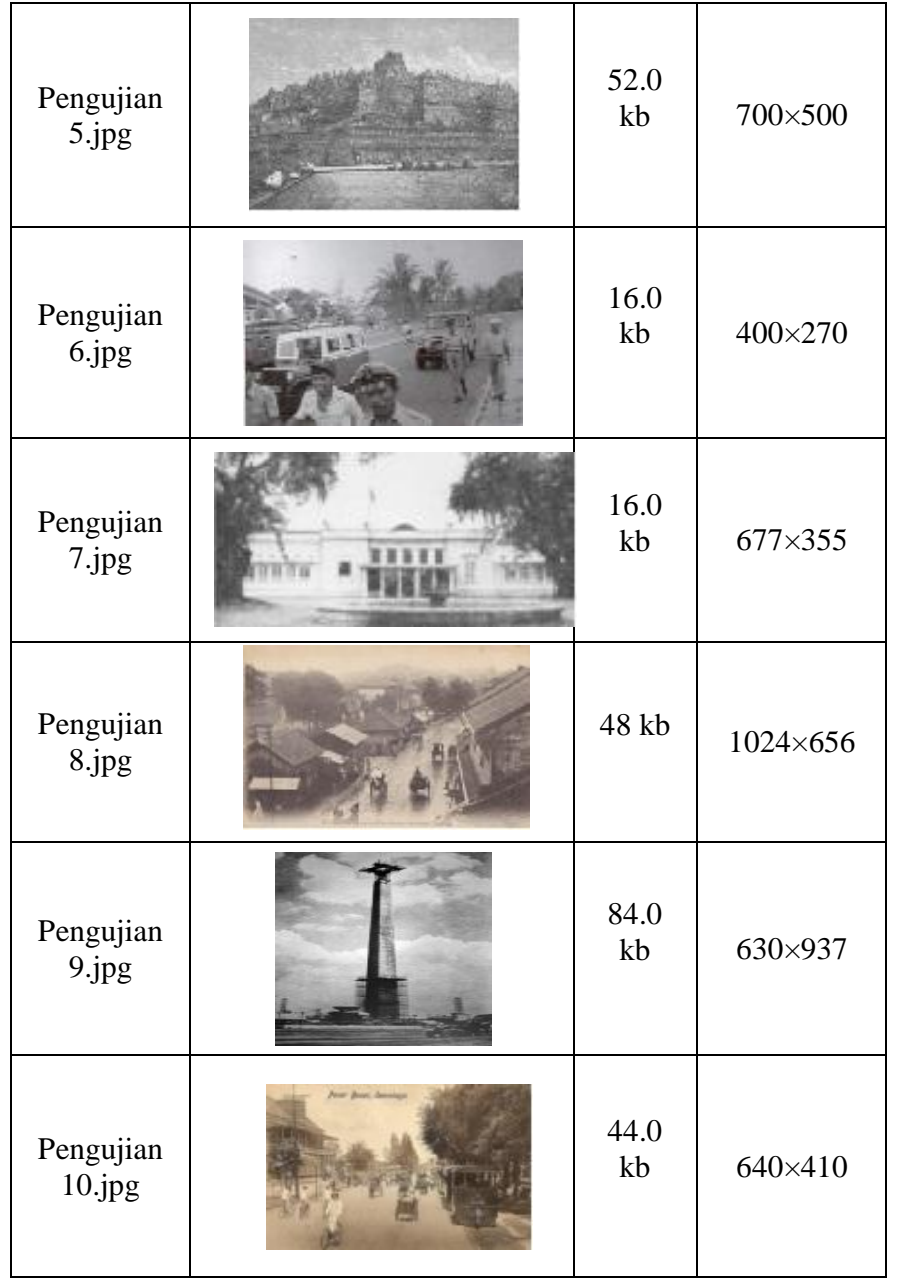

From the process of noise reduction using Gaussian filter on the table 2, all images affected by noise which has different kind and size have succeed to reduce noise using Gaussian filter. The result of noise reduction process creates output of image which is different from before using Gaussian filter. The format changes to jpg and the result of noise reduction is blurrier than the original one. It is caused by effect of filtering and Gaussian. The image size of noise reduction using Gaussian filter is smaller than the original one and the pixel is the same as the original one.

\subsection{Calibrating Image Quality}

Root Mean Squared Error (RMSE) is used to measure error level of filtering result by comparing with the original one. The bigger value of RMSE is created, the bigger error level of filtering result is created. It makes the image created more different from the original one.

Peak Signal to Noise Ration (PSNR) is used to compare between maximum value of signal measured and the size of noise which affects that signal. PNSR is a standard parameter to evaluate image quality objectively by comparing PNSR. The bigger value of PSNR is created, the more similar image is created.

Signal to Noise Ration (SNR) is used to measure quality of signal. It is measured based on the original image and the image which is the result of filtering. The bigger value of SNR is created, the better signal is created.

Table 3. Image which is The Result of Noise Reduction

\begin{tabular}{|c|c|c|c|}
\hline Image & RMSE & PSNR & SNR \\
\hline Pengujian1.Jpg & 1185.5739 & 17.3915 & 13.2861 \\
\hline Pengujian2.Jpg & 19.2960 & 35.2761 & 30.9538 \\
\hline Pengujian3.Jpg & 417.6772 & 21.9224 & 14.7823 \\
\hline Pengujian4.Jpg & 851.3292 & 18.8298 & 15.2837 \\
\hline Pengujian5.Jpg & 384.1080 & 22.2863 & 18.1196 \\
\hline Pengujian6.Jpg & 212.7200 & 24.8527 & 20.2582 \\
\hline Pengujian7.Jpg & 366.4931 & 22.4901 & 19.4497 \\
\hline Pengujian8.Jpg & 214.6883 & 24.8127 & 20.4312 \\
\hline Pengujian9.Jpg & 280.9278 & 23.6449 & 19.8898 \\
\hline Pengujian10.Jpg & 1027.3495 & 18.0136 & 13.0657 \\
\hline
\end{tabular}

From the table 3, it indicates that the biggest value of RMSE is in the pengujian1 jpg. It is caused by the result of noise reduction different from the original one which is affected by noise. The biggest PNSR is in the pengujian2.jpg. SNR is in pengujian $2 \mathrm{jpg}$. The smallest RMSE is in the pengujian $2 \mathrm{jpg}$. The PSNR and SNR are in pengujian $2 \mathrm{jpg}$. The result of noise reduction which is the most similar to the original one is in the pengujian $2 \mathrm{jpg}$. The value of RMSE is $1185.5739 \mathrm{db}$, PSNR:17.3915db, SNR:13.2861db. The most similar to the original one is in the pengujian $2 \mathrm{jpg}$. The value of RMSE is 19.2960db, PSNR:35.2761db, SNR 30.9538db.

\section{CONCLUSSION}

Based on the result of Gaussian filtering process, there are some conclusions.

1) The process of image smoothing to reduce noise using Gaussian filter creates an image better than before doing noise reduction.

2) To disentangle noise using Gaussian filtering based on the result of image smoothing process succeed to disappear effect of noise using Gaussian filtering, but it creates an image blurrier than the original one. It is caused by effect of Gaussian filtering. The size of image is smaller than the original one.

3) The image formats which are possible to process using Gaussian filter are PNG, JPG, and BMP.

4) The result of noise reduction which is the most similar to the original one is in the pengujian $2 \mathrm{jpg}$ which the value of RMSE is $1185.5739 \mathrm{db}$, PSNR: $17.3915 \mathrm{db}$, SNR:13.2861db and the most different is in the pengujian $1 \mathrm{jpg}$ which the value of RMSE is 19.2960 , PSNR:35.2761, SNR 30.9538db

5) The image size using Gaussian filter is smaller than the original one.

6) The biggest value of RMSE is in the pengujian $1 \mathrm{JPG}$. It caused by the noise reduction different from the original one. The biggest PSNR is in the pengujian 2 JPG. The SNR is in the pengujian $2 \mathrm{JPG}$. The smallest RMSE is in the pengujian 2 JPG. The PSNR and SNR are in the pengujian $2 \mathrm{JPG}$. 


\section{ACKNOWLEDGMENTS}

Our thanks to the experts who have contributed towards development of the template.

\section{REFERENCES}

[1] Purwandani, Dessy. "Implementasi Metode Gaussian Smoothing untuk Penghalusan Citra (Image Smoothing), " Program Studi Teknik Informatika STMIK Budi Darma Medan, ISSN : 2301-9425, no:2, Maret 2015.

[2] Gazali, Wikaria and Soeparno, Haryono. "Perancangan Program Aplikasi Pengurangan Noise Pada citra Digital menggunakan Metode Berbasis Wavelet" Teknik Informatik,Fakultas ilmu Komputer Universitas Bina Nusantara Jakarta Barat, Jurnal ISSN 76-86, Vol 10 2010 .

[3] Yuwoso, Bambang. 'Image Smoothing Menggunakan Mean Filtering, Media Filtering, Modus Filtering dan Gaussian Filtering",Teknik Informatika UPN Veteran Yogyakarta,ISSN 1829-667X Vol-7, No.1:65-75 Juli 2010 .

[4] Wedianto, Andre., Sari, Herlina Latipa., and Suzantri H, Yanolanda. "Analisa Perbandingan Metode Filter Gaussian, Mean dan Median Terhadap Reduksi Noise", Teknik Komputer Fakultas Ilmu Komputer Universitas Dehasen Bengkulu,ISSN 1858-2680, Vol.12 no.1 Febuari 2016.

[5] Heryana, Nono., and Mayasari, Riri., "Implementasi Noise Removal Menggunakan Wiener Filter untuk Perbaikan Citra Digital," UNSIKA, Teknik Informatika Vol.5, No.2, 159-164 2016.

[6] Praveen, K Siva., Hamarnath,G., Babu,K. Prasad., Sreenivasulu,M., and Sudhakar,K., 2016 "Implementation of Image Sharpening and Smoothing Using Filters” Department of ECE, SJCET Yemmiganur, Andhra pradesh, India.Januari 2016.

[7] Verma,Anurag., and Mishra, Prof. Abhishek., 2015 "Image Compression using Gaussian Smoothing Filter and Median Filter" Dept. Of Electronics and communication United institute Of technology Allahabad,U.P. November 2015.

[8] Tyagi,Tarun., and Mishra, Vishal.,"2D Gaussian Filter For Image Processing Aplication on FPGA 'Department of Electronics Engineering Ideal Institute of Technology, Ghaziabad IJSTE,ISSN: 2349-784X, Vol.3,Issue 06, Desember 2016.

[9] Patidar,Pawar Kumar., Singh,Lali Baldev., and Bagaria, Gaurav., " Image Filtering using Linar and Non Linear Filter for Gaussian Noise" Institute of Technology Rajasthan Technical University, Computer Science Department, India IJOCP(0975-8887) Vol 93-no 8,may 2014.

[10] Yuan, Y B., Piao, W Y., and Xu.,J B.,"A fast Gaussian filtering algorithm for three-dimensional surface roughness measurements," Harbin Institute of Technology (HIT), Harbin, China, ISIST, Journal of Physics: Conference Series 48 (2006) 1401-61, 2016.

[11] Shaikh, Md. Shahnawaz., Choudhry,Ankita., and Wadhwani, Rakhi.,"Analysis of Digital Image Filters in Frequency Domain," Department of ECE SDITS Khandwa, IJCA:0975-8887, Volume 140-No.6, April 2016.

[12] Vijaykumar,V.R.,Vanathi,P.T. and P.Kanagasabapathy., "Fast and Efficient Algorithm to Remove Gaussian Noise in Digital Images, "IAENG International Journal of Computer Science, 37:1, IJCS_37_1_09, February 2010.

[13] Swaminathan,R.,"Application of Spatial Domain Filters on Noisy Images using MATLAB, "Urumu Dhanalakshmi College, Kattur Tiruchirapalli -19 International Journal of Computer Applications (0975 8887) Volume 134 - No.2, January 2016,Tamilnadu, India.

[14] Kumar V,Manoj., Philip,Remya Elizabeth., Arun A, and Sumithra M G "Comparative Analysis of Different Filters for Denoising in Medical Image," PG Student, Dept. of ECE, Bannari Amman Institute of Technology, Sathyamangalam, Tamil nadu, India, IJIRSET, Vol.2,Issue 3,ISSN:2319-8753,March 2013.

[15] Mezher, Liqaa S.,"Digital Image Processing Filtering with LABVIEW, "Department of Electrical Engineering Al-Mustansiriyah University Baghdad - Iraq ,I JCS T) Volume 4 Issue 4, Jul - Aug 2016.

[16] Kabbai,Leila., Sghaiery,Annisa., Douik, Ali., and Mohsen Machhout, Mohsen., "FPGA implementation of filtered image using 2D Gaussian filter, "Faculty of sciences Monastir, University of Monastir-Tunisia, IJACSA Vol. 7, No. 7, 2016.

[17] Nagu,Malothu., and Shanker., N. Vijay., "Image DeNoising By Using Median Filter and Weiner Filter," Department of ECE, VKR,VNB\&AGK College of Engineering, Gudivada, Krishna(Dt), Andhra Pradesh, India, IJRCCE, Vol. 2, Issue 9, September 2014.

[18] Srivastava, Chanchal., Mishra,Saurabh Kumar., Pallavi Asthana, Mishra,G.R., and Singh,O.P., "Performance Comparison of Various Filters and Wavelet Transform for Image De-Noising," Amity School of Engineering \& Technology Amity University Uttar Pradesh Lucknow Campus, India, IOSR-JCE, 8727Volume 10, Apr. 2013.

[19] Chahar, Pratap Singh., Thakare, Vandana Vikas., "Performance Comparison of Various Filters for Removing Gaussian and Poisson Noises," MadhavInstitute of Technology \& Science, Gwalior, India, IRJET, Volume: 02 , Aug-2015.

[20] Malathi, K., and Nedunchelian, R., "Comparision of Varios Noise and Filters for Fundus Images Using PreProcessing Techniques," Saveetha School of Engineering, Saveetha University, Int J Pharm Bio Sci, 5 (3), 499 - 508, July 2012. 